\title{
Review article: Accelerated Starvation of Childhood - Have I Judged Ketones?
}

Robert Millar ${ }^{1,2,3}$ and Anton Harding ${ }^{1,2,3,4}$

${ }^{1}$ University of Melbourne, Melbourne, Australia

${ }^{2}$ Austin Hospital, Melbourne, Australia

${ }^{3}$ Epworth Hospital, Melbourne, Australia

${ }^{4}$ Royal Children's Hospital, Melbourne, Australia

Robert Millar, MBBS DCH GradDipPaed FACEM. Paediatric Emergency Physician. Honorary Clinical Lecturer, University of Melbourne.

Anton Harding, BSc(Hons) MBBS FRACP(Paed). Paediatrician, Paediatric Endocrinologist. Clinical Tutor, University of Melbourne.

Contributions:

Dr. Millar conceived, drafted, edited, and submitted the article, and gained case consents.

Competing interests: None declared

Dr. Harding reviewed and edited the article.

Competing interests: None declared

Word count: 2485

Correspondence details:

Dr Robert Millar

Email: robert.millar@austin.org.au,or rob.millar.777@gmail.com

Phone: 0417111989

Address: 2 Yileen Court, Donvale, VIC 3111

\section{Accelerated Starvation of Childhood: Have I Judged Ketones?}

Robert Millar ${ }^{1,2,3}$ and Anton Harding ${ }^{1,2,3,4}$

This is the author manuscript accepted for publication and has undergone full peer review but has not been through the copyediting, typesetting, pagination and proofreading process, which may lead to differences between this version and the Version of Record. Please cite this article as doi: 10.1111/1742-6723.13276

This article is protected by copyright. All rights reserved. 
${ }^{1}$ University of Melbourne, Melbourne, Australia

${ }^{2}$ Austin Hospital, Melbourne, Australia

${ }^{3}$ Epworth Hospital, Melbourne, Australia

${ }^{4}$ Royal Children's Hospital, Melbourne, Australia

Robert Millar, MBBS DCH GradDipPaed FACEM. Paediatric Emergency Physician.

Honorary Clinical Lecturer, University of Melbourne.

Anton Harding, BSc(Hons) MBBS FRACP(Paed). Paediatrician, Paediatric

Endocrinologist. Clinical Tutor, University of Melbourne.

Competing interests: None declared

Keywords: child, glucose, ketones, ketosis, starvation

\begin{abstract}
Acute ketosis is an important physiological mechanism to prevent irreversible neurological damage from hypoglycaemia, and represents a significant metabolic stress. A cohort of children adapt to relatively short periods of reduced caloric intake by generating large quantities of ketone bodies. When excessive, the gastrointestinal symptoms of starvation ketosis such as nausea and pain may create a vicious cycle which delays spontaneous resolution. The presence of ketones can be dismissed as a
\end{abstract}


normal feature of childhood metabolism, sometimes even when extreme. A broader understanding of this process under the banner of "accelerated starvation of childhood" is helpful for clinicians managing acute illness in children. We advocate that children less than 7 years of age with a history suggestive of accelerated starvation of childhood should be screened by Emergency clinicians for ketosis using a simple and cheap bedside capillary test, even if glucose levels are greater than 2.6 $\mathrm{mmol} / \mathrm{L}$. Identification and appropriate management of ketosis may alleviate the distressing gastrointestinal symptoms associated with many minor illnesses, and potentially prevent hypoglycaemia in some children. Appropriate advice to carers may be helpful to prevent further episodes. Illustrative case examples from our own practice are provided.

\section{Introduction}

An accelerated version of starvation ketosis is known to occur in some children, most frequently males aged 6 months to 6 years of age, when deprived of caloric intake for a short period.1,2 This is usually a complication of an intercurrent illness such as gastroenteritis, but may also occur in the context of pre-operative fasting. ${ }^{3}$ During Emergency Department (ED) assessment elevated ketone levels may sometimes be detected in blood or urine but dismissed as a "normal" feature of childhood metabolism, and not specifically addressed during clinical management. However, the gastrointestinal symptoms of ketosis such as 
abdominal pain and nausea may reduce caloric intake even further, driving a vicious cycle into ketoacidosis. The presence of ketones may also serve as an important early warning of impending hypoglycaemia, with the risk of potentially irreversible CNS damage. ${ }^{4}$ Early detection of ketosis could therefore be used as a trigger to guide therapy, as well as advice regarding fasting periods during subsequent illnesses. ${ }^{4}$

We advocate that screening for ketosis as well as hypoglycaemia is appropriate in children who present with a seizure, lethargy, or vomiting for more than 24 hours. Those with ketone levels greater than $2.5 \mathrm{mmol} / \mathrm{L}$ are likely to benefit from specific therapy. We also propose that the modern terminology of "accelerated starvation" is a better descriptor than "ketotic hypoglycaemia" as not all cases present with a glucose level below the normal reference range.

\section{Methods}

A literature search was undertaken of Medline (OVID) and PubMed, using MeSH search terms "child", "glucose", "ketones", "ketosis" and "starvation". Full texts of relevant articles were obtained with the assistance of a medical librarian, and reference lists screened for further relevant articles. Consent for publication of case studies was obtained from legal guardians and an ethics exemption gained from the Austin Health Human Research Ethics Committee. 


\section{Background}

The phenomenon of ketosis in a vomiting child has been observed since at least the early 1900s when Antoine Marfan published a paper describing children who presented with recurrent vomiting and were found to have acetonuria. ${ }^{5}$ Marfan, who wrote on a wide range of paediatric topics, later published two editions of a book entitled "Les Vomissements périodiques avec acétonémie". 6 Ross and Josephs made further observations on the metabolism of affected children in the $1920 \mathrm{~s},{ }^{7,8}$ and Josephs also noted a link with convulsions. ${ }^{9}$ Later work by Weymuller and Schloss showed that while hypoglycaemia was often present in normal children after fasting for 48 hours, it was the propensity to rapidly develop "nondiabetic ketosis" that set the symptomatic children apart.10,11 It was not until 1964 until that Colle and Ulstrom characterised in more detail the children who recurrently presented with "ketotic hypoglycemia" (KH). ${ }^{12}$ They also described management that remains largely unchanged 5 decades later, both enteral and parenteral, and proposed home testing of urinary ketones for these children when unwell. At that time the only available test for ketones was for acetone, although beta-hydroxybutyrate is now the more commonly measured ketone as it can be detected in blood and also excreted in urine. 


\section{Case 1: Classical "ketotic hypoglycaemia"}

A 16 month-old boy $(10.7 \mathrm{~kg})$ presented with a 3-day history of vomiting without diarrhoea. He had been drinking water, and had a couple of teaspoons of apple puree in the evening. In the morning he was very drowsy, and the responding ambulance crew measured a glucose level of $1.2 \mathrm{mmol} / \mathrm{L}(2.8-7.2)$, which was treated with two IM doses of glucagon without improvement. Past history included delivery at 36 weeks as the second twin, and peanut allergy. $\mathrm{He}$ arrived in ED at 08:34 responsive to painful stimuli, HR 120, CRT $<2 \mathrm{sec}$, glucose $1.4 \mathrm{mmol} / \mathrm{L}$, ketones $3.9 \mathrm{mmol} / \mathrm{L}(<0.6)$, and bicarbonate $13 \mathrm{mmol} / \mathrm{L}(19$ - 25). IV access was achieved, a critical sample taken, $27 \mathrm{ml}$ of $10 \%$ glucose given, then maintenance fluids of $0.9 \%$ saline \& $5 \%$ dextrose. Within 2 hours he was alert and his glucose was $6.4 \mathrm{mmol} / \mathrm{L}$ and ketones $1.9 \mathrm{mmol} / \mathrm{L}$. Hormone levels from the critical sample were normal and he was discharged the next day with dintomenderion

Under the banner of "ketotic hypoglycaemia" much of the research focus, even into the $21^{\text {st }}$ century, has been on those children who present with hypoglycaemia in concert with their ketosis, ${ }^{2}$ although some researchers had acknowledged that ketosis is not always accompanied by hypoglycaemia. ${ }^{13-15}$ The prevalence of hypoglycaemia in non-diabetic patients 1-5 years old presenting to the ED has been reported as 6.54 per 100,000 presentations when defined as $<2.6 \mathrm{mmol} / \mathrm{L}, 16$ and hypoglycaemia with ketosis ("ketotic hypoglycaemia") has been found in approximately 4 per 100,000 presentations in retrospective studies. ${ }^{2,16}$ However in our experience the prevalence of ketosis with euglycemia is much higher. More recently use of the nomenclature “accelerated starvation" (previously utilised mainly to describe a syndrome of pregnancy ${ }^{17}$ has been helpful as it allows a broader view to include ketotic patients who may not be technically hypoglycaemic. 
The mechanism of this disorder is not well understood, but is likely to be due to lipolysis triggered when processes such as glycogenolysis and gluconeogenesis are inadequate to provide metabolic glucose requirements (see Figure 1). ${ }^{18}$ This may explain the unresponsiveness to exogenous Glucagon that has been described during ketotic hypoglycaemia. ${ }^{19}$ Once hepatic glycogen stores are depleted, and then substrate for gluconeogenesis is also consumed, insulin levels fall with consequent reduction of inhibition of lipolysis, allowing fatty acid oxidation \& ketogenesis. ${ }^{4}$ This is an important physiological rescue mechanism in order to provide substrates (ketone bodies) that will cross the blood-brain barrier to sustain vulnerable neurones. ${ }^{20,21}$ Children known to develop ketosis have lower insulin levels than controls when on a ketogenic diet, while their glucagon levels are higher. ${ }^{22}$ Accelerated starvation is therefore associated with elevated levels of ketones, free fatty acids, glucagon, and cortisol. Insulin levels are low, as is the concentration of plasma alanine, the major amino acid substrate for gluconeogenesis. ${ }^{4}$ The observation of low alanine levels in ketotic hypoglycaemia was postulated to be its cause in the $1970 \mathrm{~s},{ }^{23}$ however this was subsequently shown to be a consequence of alanine depletion by gluconeogenesis rather than a pre-existing cause of its failure. ${ }^{24}$

A convincing unifying physiological explanation remains elusive. It may be that a heterogenous group of metabolic disorders are contributing factors. ${ }^{25}$ Glycogen 
synthase deficiency, ${ }^{26}$ glycogen storage disorders, ${ }^{15,27}$ and

monocarboxylate transporter 1 deficiency ${ }^{14}$ are three such contributors. Some affected children are thought by some researchers to be those with metabolic processes that are slow to develop, ${ }^{28}$ and may represent the tail of the Gaussian curve of metabolic maturity. ${ }^{29}$ This is supported by the observation that affected children are often below average weight for age and that fasting tolerance improves with increased body mass. ${ }^{1}$ The fact that these children begin presenting with this phenomenon only after several months of age might counter a hypothesis based on simple maturation, ${ }^{30}$ however this may relate to increasing intervals between feeds at this age. Regardless of the underlying cause, this phenomenon represents intolerance for fasting due to a mismatch between glucose utilisation and production, ${ }^{18}$ and due to its important consequences requires identification and appropriate management.

\section{Case 2: Ketoacidosis without hypoglycaemia}

A 12 month-old girl $(6.8 \mathrm{~kg})$ arrived overnight with a 3-day history of coryza and non-bilious vomiting. She had become lethargic and was sleeping most of the day. Wet nappies were decreased. Past history was of a normal 38-week delivery, normal development, and immunisations per schedule.

She was afebrile, HR 127, CRT $<2 \mathrm{sec}, \mathrm{SpO} 298 \%$, chest was clear, and she had a mildly erythematous right tympanic membrane. Capillary glucose was 3.7

$\mathrm{mmol} / \mathrm{L}$, ketones $3.7 \mathrm{mmol} / \mathrm{L}$, and bicarbonate $14 \mathrm{mmol} / \mathrm{L}$. Urine dipstick showed ketones only. Intravenous $0.9 \%$ saline \& $5 \%$ dextrose was commenced, and by the evening vomiting has ceased, she was feeding well, glucose was $5.6 \mathrm{mmol} / \mathrm{L}$ and ketones $1.9 \mathrm{mmol} / \mathrm{L}$.

Ketoacidosis, at the most severe end of the ketosis spectrum, has many other causes that need to be excluded (see Figure 2). Diabetic ketoacidosis (DKA) usually differs 
due to its presentation with hyperglycaemia, as euglycaemic diabetic ketoacidosis is a rare occurrence ${ }^{31}$ most commonly reported in recent times due to use of SGLT2 inhibitors. ${ }^{32}$ Drug toxicity (e.g. salicylates), ${ }^{33}$ inborn errors of metabolism, ${ }^{15,34}$ anorexia nervosa, ${ }^{35}$ and low-carbohydrate diets designed to induce mild ketosis may also trigger ketoacidosis. ${ }^{36}$ Other forms of euglycaemic or hypoglycaemic ketosis are described in adults after alcohol binges, ${ }^{35,37}$ while pregnant, ${ }^{17,35,38}$ and during lactation. ${ }^{39}$ These episodes have also been referred to as "accelerated starvation". In order to distinguish the phenomenon in fasting children it may be useful to update the nomenclature of Pierides et al ${ }^{40}$ from "Ketotic hypoglycaemia of childhood" to "Accelerated starvation of childhood" (ASC). As stated earlier, rather than just a name change this also helpfully broadens the scope to include not only children with hypoglycaemia, but a larger cohort with ketosis (or ketoacidosis) and euglycaemia who also need to be identified and managed appropriately. ${ }^{35}$

\section{Clinical assessment \& management}

ASC often presents in the morning after the longest fast of the day. Symptoms include lethargy, nausea, vomiting, abdominal pain, and sometimes seizures. ${ }^{1,2,9}$ These symptoms may also be overlaid on the symptoms of the precipitating illness. ASC is the most common cause of childhood hypoglycaemia, but ketosis often precedes 
hypoglycaemia by several hours, such that ketosis may be present while euglycaemic. $^{12}$ The degree of ketosis and acidosis often seems out of proportion to relatively mild dehydration. The milder end of the spectrum may be misdiagnosed as a gastrointestinal illness such as viral gastritis, gastroenteritis, mesenteric adenitis, abdominal migraine, or cyclic vomiting syndrome. ${ }^{41}$ However, at it's most extreme it can present with coma and Kussmaul breathing requiring resuscitation and critical care interventions. In a published case series of 7 admissions with bicarbonate levels as low as $3 \mathrm{mmol} / \mathrm{L}$, only 2 of which were associated with hypoglycaemia, insulin and glucose infusions as well as continuous renal replacement therapy were required. ${ }^{42}$

Urine dipstick tests for ketones are semi-quantitative, and specimens are difficult to obtain on demand. The most useful quantitative test for ketones during assessment in the modern ED is a bedside capillary blood test for beta-hydroxybutyrate (BHB), ${ }^{43}$ most commonly utilised for patients suspected of having DKA (see Figure 3 for reference ranges). This can usually be achieved after a single finger-prick to measure both glucose and ketones. In the same way that Anaesthetists have been encouraged to test ketone levels in children after extended fasting for surgery, ${ }^{3}$ Emergency clinicians should consider screening for ASC with bedside capillary testing when young children present with suggestive symptoms during an illness that has prevented them from eating. ${ }^{44}$ Assessment of hydration state is routinely undertaken in these circumstances, and metabolic disturbance should be assessed in parallel. 
An important question is at what level should ketosis be considered abnormal? A BHB level of $<0.6 \mathrm{mmol} / \mathrm{L}$ is usually considered normal. Advocates of lowcarbohydrate diets usually suggest targeting a level above $0.5 \mathrm{mmol} / \mathrm{L}$, and up to 3.0 mmol/L. ${ }^{45,46}$ Our practice suggests that children with symptomatic ketosis usually have BHB levels $>2.5 \mathrm{mmol} / \mathrm{L}$ (see cases 1,2 and 3 ). As a comparison, the last ten paediatric DKA cases at our institution had a median ketone level of 4.75 (range 3.2 7.0), demonstrating that the ketosis of ASC can be just as profound as in DKA. Published data on this aspect includes a study by Van Veen and colleagues of otherwise normal children undergoing a medically supervised fasting tolerance test to investigate possible hypoglycaemia. ${ }^{4}$ They demonstrated that the median BHB level at 20 hours of fasting for a child less than 24 months of age was $2.23 \mathrm{mmol} / \mathrm{L}\left(90^{\text {th }}\right.$ centile 3.31), the median at 24 hours for a child 2-7 years of age was $2.01 \mathrm{mmol} / \mathrm{L}$ $\left(90^{\text {th }}\right.$ centile 3.54$)$, and the median for children $7-18$ years of age at 24 hours was 1.31 $\mathrm{mmol} / \mathrm{L}\left(90^{\text {th }}\right.$ centile 2.46$)$. Based on this data a BHB level of more than $3.5 \mathrm{mmol} / \mathrm{L}$ is therefore extremely high, and represents a very poor adaption to starvation and a high risk for hypoglycaemia. We have judged that in ASC a BHB level above a threshold of $2.5 \mathrm{mmol} / \mathrm{L}$ is a level at which medical intervention and monitoring is warranted until the risks are abated (see Figure 4).

Management of ASC consists of providing a carbohydrate source, initially sugars such as glucose, and then foods containing complex carbohydrates. ${ }^{12}$ The resulting insulin secretion inhibits lipolysis and eventually reverses ketoacidosis. Exogenous 
insulin is only necessary in the most severe cases with profound acidosis, but appears to provide more rapid resolution than bicarbonate infusion or renal replacement therapy in those that are critically unwell. ${ }^{42}$

Management of otherwise "simple" gastroenteritis and other viral illnesses often focuses exclusively on hydration, but if ketosis is identified treatment should include provision of a carbohydrate source. ${ }^{35}$ While oral therapy has advantages, our experience is that the profound nausea often reduces its efficacy. If intravenous therapy is required most children will receive fluids containing at least $5 \%$ glucose $(50 \mathrm{~g} / \mathrm{L})$ as a matter of course to prevent hypoglycaemia. Previously it has been observed that children with gastroenteritis treated with intravenous glucosecontaining fluids have more rapid reduction of ketone levels than those treated with normal saline, and a non-significant trend towards reduction in admission rate. ${ }^{47}$ It has also been demonstrated that the rate of re-presentation admissions is significantly lower in children who have glucose administered on their first presentation with gastroenteritis, independent of the volume of fluid administered. ${ }^{48}$ These outcomes are unlikely to be due to glucose causing an improvement in hydration, but due to an effect on improving acid-base state by reversing ketosis. Further research to examine this relationship in a larger cohort is warranted.

Enteral therapy is possible although the default oral rehydration solutions (ORS) are often not sufficient to fully reverse ketosis and the associated symptoms, as 
demonstrated in case 3 . ORS contains only enough glucose $(16 \mathrm{~g} / \mathrm{L})$ to facilitate sodium absorption from the gut, whereas breastmilk and infant formulas (approx. $68 \mathrm{~g} / \mathrm{L}$ sugars) are better suited to reversing ketosis in infants. Older children may be more amenable to cow's milk (45 g/L), fruit juice $(75-100 \mathrm{~g} / \mathrm{L})$, or lemonade (100$120 \mathrm{~g} / \mathrm{L})$ if available. Glucose powder $(5 \mathrm{~g} / \mathrm{tsp})$ dissolved in water then a sandwich (approx. 30g of carbohydrate from 2 slices of bread) is another option. An antiemetic such as ondansetron may assist with tolerance of oral intake.

\section{Case 3: ASC not responsive to hydration alone}

An 8 month-old girl $(7.65 \mathrm{~kg})$ presented to ED after 24 hours of coryza, vomiting and poor feeding. She had 2 wet nappies in the preceding 12 hours. Past history included maternal gestational diabetes, but no episodes of neonatal hypogycaemia. Her HR was 134, CRT $<3$ seconds, and chest was clear. Her initial capillary glucose was $3.0 \mathrm{mmol} / \mathrm{L}$, and ketones $5.9 \mathrm{mmol} / \mathrm{L}$. Ondansetron was given, followed by $140 \mathrm{ml}$ of oral rehydration fluid. Subsequent glucose was $3.2 \mathrm{mmol} / \mathrm{L}$, and ketones $6.6 \mathrm{mmol} / \mathrm{L}$. Nasogastric rehydration with ORS was commenced at a maintenance rate overnight in the short stay unit. The following morning she was well hydrated but still not feeding. Glucose was $3.4 \mathrm{mmol} / \mathrm{L}$ and ketones 3.3 $\mathrm{mmol} / \mathrm{L}$. The nasogastric fluid was changed to infant formula, which rapidly led to normalisation of glucose $\&$ ketones hefore discharge.

Prevention of ASC in those affected relies on the regular provision of carbohydrates during the day and a snack before bedtime, especially during illness. ${ }^{12}$ Ketogenic diets should be avoided. Recurrent episodes may warrant home testing of ketones in a similar manner to patients with diabetes. Unless an inborn metabolic disorder is present parents can be reassured that the tolerance for fasting will improve as the child grows. Where metabolic disorders are suspected (e.g. developmental delay, 
hepatomegaly, profound hypoglycaemia) the diagnosis may be assisted by collection of a critical sample taken at the point of presentation with hypoglycaemia (see Figure 5), during a medically controlled fast, ${ }^{49}$ or via genetic testing (blood samples collected in an EDTA tube are now preferable to a Guthrie card, personal correspondence: Dr James Pitt, Victorian Clinical Genetics Services).

\section{Conclusion}

Children less than 7 years of age with a history suggestive of accelerated starvation of childhood should be screened for ketosis, even if glucose levels are greater than 2.6 mmol/L. Although true hypoglycaemia may be somewhat rare among ED presentations of non-diabetic patients, the prevalence of ketosis or ketoacidosis is likely to be somewhat higher. Other causes of ketosis in children are less common, but should be excluded clinically or biochemically.

Treatment of ASC with a carbohydrate source helps to promptly restore normal acidbase homeostasis in most cases, whereas rehydration alone may not. Further research may provide evidence on which to base firm recommendations. Carers of children who present with ASC should be instructed to provide frequent carbohydrate snacks during periods of illness, and to seek attention if symptoms such as lethargy, vomiting, or seizure occur.

This article is protected by copyright. All rights reserved. 
ASC is benign in many cases, presenting with disturbing but readily reversible gastrointestinal symptoms, but in rare cases may herald hypoglycaemia or ketoacidosis. In appropriate patients, after addressing the “ABC”s (Airway, Breathing, Circulation) and "DEFG” (Don't Ever Forget Glucose) ${ }^{50}$, emergency clinicians should be encouraged to consider "HIJK" (Have I Judged Ketones?). 


\section{References}

1. Habbick BF, McNeish AS, Stephenson JB. Diagnosis of ketotic hypoglycaemia of childhood. Arch Dis Child. 1971;46(247):295-300

2. Daly LP, Osterhoudt KC, Weinzimer SA. Presenting features of idiopathic ketotic hypoglycemia. J Emerg Med. 2003;25(1):39-43.

3. Dennhardt N, Beck C, Huber D et al. Impact of preoperative fasting times on blood glucose concentration, ketone bodies and acid-base balance in children younger than 36 months: A prospective observational study. Eur J Anaesthesiol. 2015;32(12):85761

4. van Veen MR, van Hasselt PM, de Sain-van der Velden MG et al. Metabolic profiles in children during fasting. Pediatrics. 2011;127(4):e1021-7

5. Marfan AB. Les vomissements avec acétonémie chez les enfants. Arch. de Méd. d. Enf. 1901;4(11):641-658

6. Marfan AB. Les Vomissements périodiques avec acétonémie, $2^{\text {nd }}$ edn. Masson, Paris, 1926.

This article is protected by copyright. All rights reserved. 
7. Ross SG, Josephs HW. Observations on the metabolism of recurrent vomiting, Am. J. Dis. Child. 1924;28: 447

8. Josephs H. Recurrent vomiting, Am. J. Dis. Child. 1926;31: 655

9. Josephs H. Fasting as a cause for convulsions, Am. J. Dis. Child. 1926;31:169

10. Weymuller CA, Schloss OM. Non- diabetic ketosis in children, Am. J. Dis. Child. $1927 ; 34: 549$

11. Schloss OM. Non-diabetic ketosis in children. Bull N Y Acad Med $1934 ; 10(8): 483-95$

12. Colle E, Ulstrom RA. Ketotic hypoglycaemia. J Pediatr. 1964;64:632-51

13. Nitzan M, Kowadlo-Silbergeld A, Doron M, Laron Z.

Metabolic substrates and hormones during starvation ketosis in children. Am J Clin Nutr. 1968;21(11):1268-73.

14. van Hasselt PM, Ferdinandusse S, Monroe GR et al.

Monocarboxylate transporter 1 deficiency and ketone utilization. N Engl J Med. 2014;371(20):1900-7

This article is protected by copyright. All rights reserved. 
15. Hoogeveen IJ, van der Ende RM, van Spronsen FJ, de Boer F, Heiner-Fokkema MR, Derks TG. Normoglycemic Ketonemia as Biochemical Presentation in Ketotic Glycogen Storage Disease. JIMD Rep. 2016;28:41-47

16. Pershad JAY, Monroe K, Atchison J. Childhood hypoglycemia in an urban emergency department: epidemiology and a diagnostic approach to the problem. Pediatr Emerg Care. 1998;14(4):268 -271

17. Metzger BE, Ravnikar V, Vileisis RA, Freinkel N. "Accelerated starvation" and the skipped breakfast in late normal pregnancy. Lancet. 1982;13;1(8272):588-92.

18. Huidekoper HH, Duran M, Turkenburg M, Ackermans MT, Sauerwein HP, Wijburg FA. Fasting adaptation in idiopathic ketotic hypoglycemia: a mismatch between glucose production and demand. Eur J Pediatr 2008;167(8):859-65

19. Court JM, Dunlop ME, Boulton TJ. Effect of ephedrine in ketotic hypoglycaemia. Arch Dis Child. 1974;49(1):63-5. 
20. Ghosh A, Banerjee I, Morris AA.

Recognition, assessment and management of hypoglycaemia in childhood. Arch Dis Child. 2016;101(6):575-80

21. Mitchell GA, Kassovska-Bratinova S, Boukaftane Y et al.

Medical aspects of ketone body metabolism. Clin Invest Med. 1995;18(3):193-216

22. Falorni A, Massi-Benedetti F, Sposito M, Barboni G, Lato M. Insulin and glucagon secretion in the ketotic (idiopathic glucagon unresponsive) hypoglycemia of childhood. J Endo Investigation. 1979;2(1):51-7

23. Donnelly PE, Turtle JR. Ketotic hypoglycaemia due to hypoalaninaemia. Med J Aust. 1974 Apr 13;1(15):573-4.

24. Wolfsdorf JI, Sadeghi-Nejad A, Senior B.

Hypoalaninemia and ketotic hypoglycemia: cause or consequence? Eur J Pediatr. $1982 ; 138(1): 28-31$.

25. Stanley CA. Parsing ketotic hypoglycaemia. Arch Dis Child. 2006;91(6):460-1. 
26. Weinstein DA, Correia CE, Saunders AC et al. Hepatic glycogen synthase deficiency: an infrequently recognized cause of ketotic hypoglycemia. Mol Genet Metab 2006;87(4):284-8

27. Brown LM, Corrado MM, van der Ende RM et al. Evaluation of glycogen storage disease as a cause of ketotic hypoglycemia in children. J Inherited Metabolic Disease. 2015;38(3):489-93

28. Dahlquist G, Gentz J, Hagenfeldt L et al. Ketotic hypoglycemia of childhood-a clinical trial of several unifying etiological hypotheses. Acta Paediatr Scand. 1979;68(5):649-56.

29. Senior B. Ketotic hypoglycemia. A tale (tail) of Gauss? J Pediatr 1973;82(3):5556

30. Rosenbloom AL. Ketotic (idiopathic glucagon unresponsive) hypoglycaemia: diazoxide effects. Arch Dis Child. 1972 Aug;47(254):544-9.

31. Jenkins D, Close CF, Krentz AJ, Nattrass M, Wright AD. Euglycaemic diabetic ketoacidosis: does it exist? Acta Diabetol. 1993;30(4):251-3.

This article is protected by copyright. All rights reserved. 
32. Isaacs M, Tonks KT, Greenfield JR.

Euglycaemic diabetic ketoacidosis in patients using sodium-glucose co-transporter 2 inhibitors. Intern Med J. 2017 Jun;47(6):701-704

33. Cartwright MM, Hajja W, Al-Khatib S et al. Toxigenic and metabolic causes of ketosis and ketoacidotic syndromes. Crit Care Clin. 2012;28(4):601-31

34. Fletcher JM. Metabolic emergencies and the emergency physician. J Paediatr Child Health. 2016;52(2):227-30.

35. Le Neveu F, Hywel B, Harvey JN. Euglycaemic ketoacidosis in patients with and without diabetes. Practical Diabetes. 2013;30(4):167-171

36. Shah P, Isley WL. Ketoacidosis during a low-carbohydrate diet. N Engl J Med. 2006;5;354(1):97-8.

37. Adams SL. Alcoholic ketoacidosis. Emerg Med Clin North Am. 1990;8(4):74960.

38. Frise CJ, Mackillop L, Joash K, Williamson C. Starvation ketoacidosis in pregnancy. Eur J Obstet Gynecol Reprod Biol. 2013;167(1):1-7

This article is protected by copyright. All rights reserved. 
39. Gleeson S, Mulroy E, Clarke DE. Lactation Ketoacidosis: An Unusual Entity and a Review of the Literature. Perm J. 2016;20(2):71-3

40. Pierides AM, Anderson J, Stansfeld JM. Ketotic hypoglycaemia of childhood. Postgrad Med J. 1975;51(600):737-41.

41. Irwin S, Barmherzig R, Gelfand A. Recurrent Gastrointestinal Disturbance: Abdominal Migraine and Cyclic Vomiting Syndrome. Curr Neurol Neurosci Rep. $2017 ; 17(3): 21$

42. Bai K, Fu Y, Liu C, Xu F, Zhu M. Pediatric non-diabetic ketoacidosis: a caseseries report. BMC Pediatr. 2017;19;17(1):209

43. O'Donohoe PB, Kessler R, Beattie TF. Exploring the clinical utility of blood ketone levels in the emergency department assessment of paediatric patients. Emerg Med J. 2006;23(10):783-7.

44. Levy JA, Waltzman M, Monuteaux MC, Bachur RG. Value of point-ofcare ketones in assessing dehydration and acidosis in children with gastroenteritis. Acad Emerg Med. 2013;20(11):1146-50

This article is protected by copyright. All rights reserved. 
45. Volek JS, Noakes T, Phinney SD. Rethinking fat as a fuel for endurance exercise. Eur J Sport Sci. 2015;15(1):13-20

46. Volek JS, Phinney SD. The Art and Science of Low Carbohydrate Living. Beyond Obesity LLC; 2011

47. Levy JA, Bachur RG, Monuteaux MC, Waltzman M. Intravenous dextrose for children with gastroenteritis and dehydration: a double-blind randomized controlled trial. Ann Emerg Med. 2013;61(3):281-8

48. Levy JA, Bachur RG. Intravenous dextrose during outpatient rehydration in pediatric gastroenteritis. Acad Emerg Med. 2007;14(4):324-30

49. Sreekantam S, Preece MA, Vijay S, Raiman J, Santra S. How to use a controlled fast to investigate hypoglycaemia. Arch Dis Child Educ Pract Ed. 2017;102(1):28-36

50. Brooks H, Harger S, Twomey P. ABC dont ever forget glucose. Br J Hosp Med. 2009;70(4):M52-3.

This article is protected by copyright. All rights reserved. 
Review article: Accelerated Starvation of Childhood - Have I Judged Ketones?

Robert Millar ${ }^{1,2,3}$ and Anton Harding 1,2,3,4

1University of Melbourne, Melbourne, Australia

${ }^{2}$ Austin Hospital, Melbourne, Australia

3Epworth Hospital, Melbourne, Australia

${ }^{4}$ Royal Children's Hospital, Melbourne, Australia

Robert Millar, MBBS DCH GradDipPaed FACEM. Paediatric Emergency Physician. Honorary Clinical Lecturer, University of Melbourne.

Anton Harding, BSc(Hons) MBBS FRACP(Paed). Paediatrician, Paediatric Endocrinologist. Clinical Tutor, University of Melbourne.

\section{Contributions:}

Dr. Millar conceived, drafted, edited, and submitted the article, and gained case consents.

Competing interests: None declared

Dr. Harding reviewed and edited the article.

Competing interests: None declared

Word count: 2485

Correspondence details:

Dr Robert Millar

Email: robert.millar@austin.org.au, or rob.millar.777@gmail.com

Phone: 0417111989

Address: 2 Yileen Court, Donvale, VIC 3111 


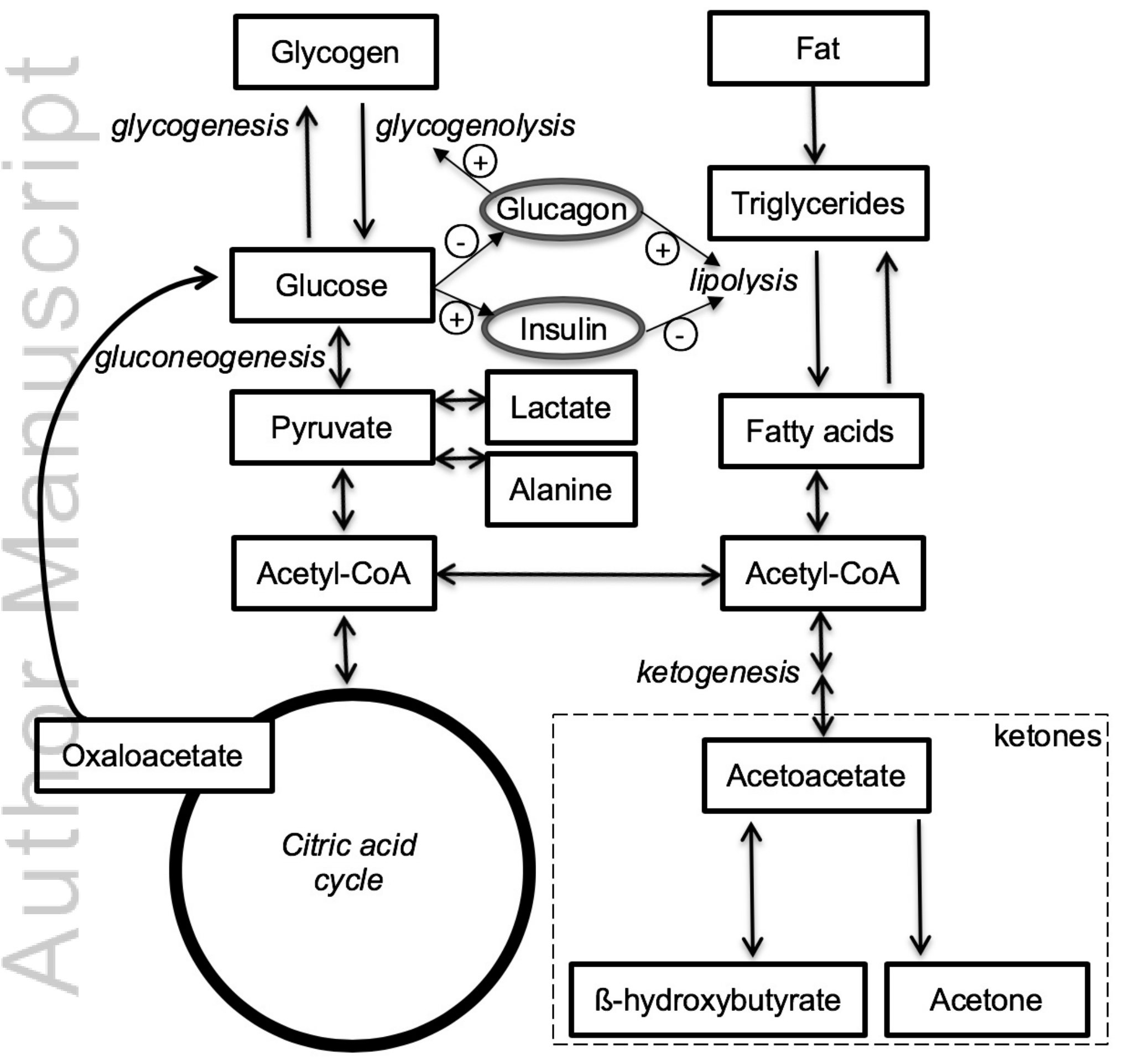

EMM_13276_Fig1_MetabolicPathways (1).jpeg 


\begin{tabular}{|l|}
\hline Figure 2: Causes of ketosis in children \\
\hline Accelerated starvation of childhood \\
\hline Diabetic ketoacidosis \\
\hline Salicylate overdose \\
\hline Ethanol \\
\hline Inborn errors of metabolism \\
\hline Anorexia nervosa \\
\hline Ketogenic diet \\
\hline
\end{tabular}

EMM_13276_Fig2_Ketosis.jpeg 


\begin{tabular}{|l|l|}
\hline \multicolumn{2}{|l|}{ Figure 3: Ketone thresholds } \\
\hline Normal & $<0.6 \mathrm{mmol} / \mathrm{L}$ \\
\hline Mild ketosis & $0.6-1.5 \mathrm{mmol} / \mathrm{L}$ \\
\hline Moderate ketosis & $1.6-2.9 \mathrm{mmol} / \mathrm{L}$ \\
\hline Ketoacidosis & $\geq 3.0 \mathrm{mmol} / \mathrm{L}$ \\
\hline
\end{tabular}

EMM_13276_Fig3_KetoneThresholds.jpeg 
History suggests accelerated starvation. Important differentials excluded.

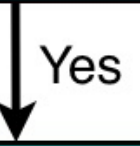

Capillary ketones high (>2.5 mmol/L)

$$
\downarrow \text { Yes }
$$

Glucose $\geq 2.6 \mathrm{mmol} / \mathrm{L}$

Conscious state not impaired.

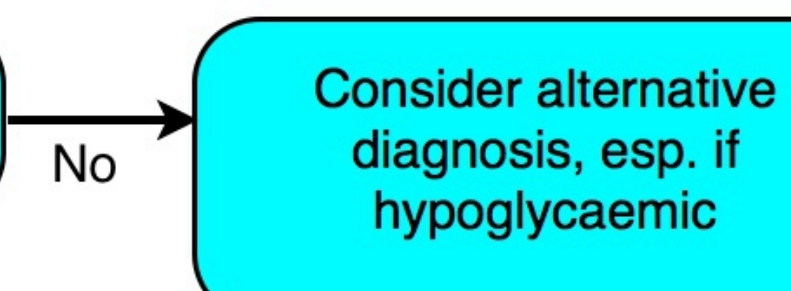

Yes

Ondanssetron

Tolerating oral glucose / carbohydrates.

Yes

Tolerating food

Glucose $>4$, Ketones $<2.5$

Yes

Discharge with followup arranged

Dietary advice to parent / carer

EMM_13276_Fig4_Algorithm.jpeg 


\begin{tabular}{|l|}
\hline $\begin{array}{l}\text { Figure 5: Critical sample tests for hypoglycaemia } \\
\text { (Adapted from RCH Clinical Practice Guidelines) }\end{array}$ \\
\hline Glucose \\
\hline Ketones (beta-hydroxybutyrate) \\
\hline Free fatty acids \\
\hline Cortisol \\
\hline Insulin \& C-peptide \\
\hline Lactate \\
\hline Carnitine / acylcarnitine \\
\hline Ammonia \\
\hline Growth hormone \\
\hline Amino acids \\
\hline Electrolytes \\
\hline Liver function tests \\
\hline $\begin{array}{l}\text { (First urine sample voided: glucose, ketones, } \\
\text { reducing substances, amino acids, organic acids) }\end{array}$ \\
\hline
\end{tabular}

EMM_13276_Fig5_HypoBloods.jpeg 


\section{University Library}

\section{- M M N E R VA A gateway to Melbourne's research publications}

Minerva Access is the Institutional Repository of The University of Melbourne

Author/s:

Millar, R;Harding, A

Title:

Review article: Accelerated starvation of childhood: Have I judged ketones?

Date:

2019-06-01

Citation:

Millar, R. \& Harding, A. (2019). Review article: Accelerated starvation of childhood: Have I judged ketones?. EMERGENCY MEDICINE AUSTRALASIA, 31 (3), pp.314-320. https:// doi.org/10.1111/1742-6723.13276.

Persistent Link:

http://hdl.handle.net/11343/285644 